\title{
Intensified glucose lowering in type 2 diabetes: time for a bolder reappraisal
}

\author{
L. Czupryniak • E. Szymańska-Garbacz • \\ M. Pawłowski • M. Saryusz-Wolska • J. Loba
}

Received: 3 October 2010 /Accepted: 19 November 2010 /Published online: 15 December 2010

(C) Springer-Verlag 2010

Keywords Diabetes complications $\cdot$ Intensive glucose lowering · Prevention · Type 2 diabetes

\section{Abbreviations \\ ACCORD Action to Control Cardiovascular Risk in Diabetes \\ VADT Veterans Affairs Diabetes Trial}

To the Editor: We read with great interest the review by Yudkin et al. [1]. The authors, having carefully analysed the available data, concluded that glucose control, while being the weakest amongst the main cardiovascular risk contributors (hypertension + hyperlipidaemia + hyperglycaemia + smoking), is being paid too much attention in the CVD prevention and treatment guidelines. They explain that if it is at all effective, it may prolong life in many patients at best for a matter of days and, furthermore, this would cost a small fortune. Moreover, in the conclusions of the article the authors suggest that intensive glucose management should be used in those individuals with higher (which we understand to mean well over $8.0 \%$ ) levels of $\mathrm{HbA}_{1 \mathrm{c}}$, particularly in those of advanced age and diminished life expectancy, and that the target of $6.5-7.0 \%$ should be completely abandoned. While we share the general view of the authors and praise their rigid analysis supported by pharmacoeconomic data, looking

L. Czupryniak $(\bowtie) \cdot$ E. Szymańska-Garbacz $\cdot$ M. Pawłowski $\cdot$

M. Saryusz-Wolska $\cdot$ J. Loba

Internal Medicine and Diabetology Department, Barlicki

University Hospital No. 1, Medical University of Lodz,

Lodz, Poland

e-mail: czupryniak@yahoo.co.uk

L. Czupryniak

e-mail: leszek.czupryniak@umed.lodz.pl at data from recent large trials we have arrived at a different conclusion regarding target $\mathrm{HbA}_{1 \mathrm{c}}$ values and the current role of intensified glucose control.

In short, the results of the Action to Control Cardiovascular Risk in Diabetes (ACCORD) study and Veterans Affairs Diabetes Trial (VADT) clearly show that aiming to reach a target $\mathrm{HbA}_{1 \mathrm{c}}$ level of $<6.5 \%$ or $<7 \%$ is beneficial for those patients with diabetes who are younger and do not have a history of micro- and macrovascular complications $[2,3]$. The ACCORD study was initially interpreted as a warning sign against lowering $\mathrm{HbA}_{1 \mathrm{c}}$ to about $6.5 \%$ [2], but the recently published analysis [4] shows that the increase in the mortality rate was largely seen only in those who failed to achieve the target levels of $6.5 \%$. Furthermore, the $\mathrm{HbA}_{1 \mathrm{c}}$ level above which the risk of death rose substantially among those in the intensive treatment arm was about $7.0 \%$, indicating that those who reached the intensive treatment target died less often than those who did not [4]. W. C. Duckworth, co-principal investigator of the VADT, announced at the American Diabetes Association meeting in June 2009: 'We found that initiation of intensive control in the first 15 years after a diagnosis of type 2 diabetes reduced the risk of cardiovascular events, including mortality, but initiation 16-20 years after diagnosis yielded no such benefit. Further, initiation of intensive control 20 or more years after diagnosis increased the risk of cardiovascular events in the population studied in this trial' [5]. A meta-analysis of the ACCORD study, Action in Diabetes and Vascular Disease: Preterax and Diamicron Modified Release Controlled Evaluation (ADVANCE) study, UK Prospective Diabetes Study (UKPDS) and VADT, performed by the Collaborators on Trials of Lowering Glucose (CONTROL) group, confirmed that achievement of an $\mathrm{HbA}_{1 \mathrm{c}}$ level of $<6.5 \%$ provides benefits 
in those whose $\mathrm{HbA}_{1 \mathrm{c}}$ was lower when entering the intensive treatment arm, those who were diagnosed with type 2 diabetes less than 5 years before and those who were free from micro- and macrovascular complications [6]. Greenfield et al. reported in their 5 year longitudinal observational study that a target $\mathrm{HbA}_{1 \mathrm{c}}$ level of $\leq 6.5 \%$ decreased CVD risk only in those type 2 diabetic patients with few rather than many comorbidities i.e. those who are 'healthier' (HR 0.6 [95\% CI $0.42-0.85]$ vs. 0.92 [95\% CI $0.68-1.25])$ [7].

It seems therefore that classifying diabetes into four types (with type 1 and type 2 as the two main ones) is probably not sufficient. We should perhaps also differentiate between patients with the same type of the disease. For instance, a 58-year-old man with newly diagnosed type 2 diabetes without any vascular complications or significant disease should be treated so that his blood glucose remains within the normal or near-normal range, thus protecting against diabetes complications (both micro- and macrovascular). In other words, when we see in our surgery a 'healthy' (without other significant health problems) type 2 diabetic patient, we should do our best to maintain his/her health and protect his/her cardiovascular system from being damaged by hyperglycaemia in the years to follow. On the other hand, if the patient is a 78-year-old man who has received treatment for type 2 diabetes for 15 years, and has a history of myocardial infarction, repeated panretinal photocoagulation and left big toe amputation, we should try to maintain his $\mathrm{HbA}_{1 \mathrm{c}}$ level somewhere between $7 \%$ and $8 \%$ (or maybe only attempting to avoid glycosuria). The pity is that diabetologists and endocrinologists mostly look after the latter kind of patients rather than the former ones, who are frequently seen by general practitioners, and that diabetologists and endocrinologists often tend to neglect the importance of intensified glucose-lowering therapy in patients treated with one or two tablets daily. It is, though, becoming apparent - and in this we beg to differ from Yudkin et al. [1] - that the majority of resources and efforts should be directed towards those younger patients who are still 'healthy', so that we may avoid complications completely in these patients, while in the older ones there is no feasible way we could reverse the damage and restore proper structure and function of cardiovascular system. However, by recommending that treatment efforts should predominantly be aimed at those with particularly poor glucose control, Yudkin et al. miss the whole group of newly or recently diagnosed patients, whose vasculature is still intact and may remain so if their blood glucose is maintained within normal levels.

Following on from this idea, perhaps we should call for future guidelines to be formulated in such a way that they would set various treatment targets and regimens for various groups of patients, depending on the stage of the disease they are at (e.g. for newly diagnosed and uncomplicated ones an $\mathrm{HbA}_{1 \mathrm{c}}$ of $<6.5 \%$; for moderately complicated, with a history of diabetes $<10$ years an $\mathrm{HbA}_{1 \mathrm{c}}$ of $<7.5 \%$; and for the elderly with long-standing diabetes and multiple complications an $\mathrm{HbA}_{1 \mathrm{c}}$ of $<8.5 \%$ ). This approach may now only be called 'common sense' or 'clinical judgment', but it would be strongly reaffirmed if it found its way into formal guidelines and recommendations.

We realise that such diversity of glucose control intensification is bad news for the medical community, as type 2 diabetes treatment will have to become more varied and thus more complicated, but at the same time it is good news for the patients, as we will be able to help each of them - as different as they are-more with doing no (or at least less) harm.

Duality of interest The authors declare that there is no duality of interest associated with this article.

\section{References}

1. Yudkin JS, Richter B, Gale EAM (2010) Intensified glucose lowering in type 2 diabetes: time for a reappraisal. Diabetologia 53:2079-2085

2. The Action to Control Cardiovascular Risk in Diabetes Study Group (2008) Effects of intensive glucose lowering in type 2 diabetes. N Engl J Med 358:2545-2559

3. Duckworth W, Abraira C, Moritz T, for the VADT Investigators et al (2009) Glucose control and vascular complications in veterans with type 2 diabetes. N Engl J Med 360:129-139

4. Riddle MC, Ambrosius WT, Brillon DJ et al (2010) Epidemiologic relationships between A1c and all-cause mortality during a median 3.4-year follow-up of glycemic treatment in the ACCORD trial. Diab Care 33:983-990

5. American Diabetes Association (2010) Factors affecting benefit/ harm of intensive glucose control in type 2 diabetes reported. Available from http://professional.diabetes.org/Congress_Display. aspx? TYP $=9 \&$ SID $=244 \& C I D=60976$, accessed 1 October 2010

6. Turnbull FM, Abraira C, Anderson RJ et al (2009) Intensive glucose control and macrovascular outcomes in type 2 diabetes. Diabetologia 52:2288-2298, Erratum 52: 2470

7. Greenfield S, Billimek J, Pellegrini F et al (2009) Comorbidity affects the relationship between glycemic control and cardiovascular outcomes in diabetes: a cohort study. Ann Intern Med 151:854-860 